4 - ORIGINAL ARTICLE

ISCHEMIA-REPERFUSION

\title{
Effects of silibinin and ethanol on skeletal muscle ischemia-reperfusion injury ${ }^{1}$
}

\author{
Yusuf Ergün', Ergül Belge Kurutaş ${ }^{I I}$, Filiz Atalay ${ }^{I I I}$, Tuğrul Alıcı ${ }^{\text {IV }}$ \\ IAssociate Professor, Department of Pharmacology, School of Medicine, Kahramanmaraş Sütçü İmam University, Turkey. Scientific, intellectual, \\ conception and design of the study, acquisition, analysis and interpretation of data, manuscript writing, critical revision, final approval of the version \\ to be published.

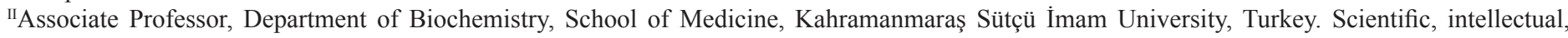 \\ conception and design of the study, acquisition and interpretation of data, final approval of the version to be published. \\ III Master of Science, Department of Biochemistry, School of Medicine, Kahramanmaraş Sütçü İmam University, Turkey. Acquisition, analysis and \\ interpretation of data, final approval of the version to be published.

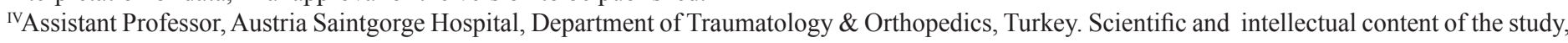 \\ critical revision, final approval of the version to be published.
}

\begin{abstract}
PURPOSE: To investigate the potential beneficial effect of silibinin in ischemia-reperfusion injury (IRI) of skeletal muscle.

METHODS: Under urethane anesthesia, four experimental groups were established in Balb/c mice: I) Sham-control, II) IRI (Tourniquet-induced) $(2+1 \mathrm{~h})$, III) IRI+ethanol (10\%), and IV) IRI+silibinin $(50 \mathrm{mg} / \mathrm{kg} / \mathrm{IP})$. The viability of muscle (left) was evaluated by the triphenyltetrazolium chloride dye method and calculated as the percentage of the contralateral control muscle (right). Malondialdehyde, superoxide dismutase, and catalase were measured in the gastrocnemius muscle via a spectrophotometer.

RESULTS:The viability of gastrocnemius muscle in group II was significantly lower in comparison with that seen in group I. The administration of either ethanol or silibinin rendered the tissues to recover nearly to the baseline level. Additionally, malondialdehyde levels were higher in group II than those in group I. The application of silibinin prior to the reperfusion attenuated these to the control levels. However, malondialdehyde levels in the ethanol administrated group were reduced as well. The enhanced superoxide dismutase activity seen in the IRI group was not diminished in the animals treated with either silibinin or ethanol. Similarly, there were no differences between groups regarding the catalase activities.

CONCLUSION: Ethanol seems to be effective in attenuating IRI in skeletal muscle and no definite conclusion can be made on silibinin effect.

Key words: Silibinin. Milk Thistle. Reperfusion Injury, Antioxidants. Muscle, Skeletal. Ethanol. Mice.
\end{abstract}




\section{Introduction}

Ischemia-reperfusion injury (IRI) of skeletal muscle exists in a variety of clinical conditions, including thrombolytic therapy, aortic cross-clamping during repair of abdominal aortic aneurysms, replantation, free tissue transfer, composite tissue allotransplantation, time-consuming reconstructive operations, tourniquet application, and crush injury ${ }^{1,2}$. Free radical generation in response to the reperfusion of ischemic skeletal muscle has been shown to be responsible for the detrimental effects ${ }^{3}$. On the basis of this view, distinct forms of antioxidants have been found to be beneficial in IRI of skeletal muscle ${ }^{2}$. Even though each item mentioned above has shown some benefit in the laboratory, none has as yet been established to have any clinical benefit. Hence, there is still a need to discover novel substances with antioxidant capacities to be utilized in IRI.

Silymarin, an extract derived from the medicinal plant Silybum marianum (milk thistle), has been used frequently in order to alleviate suffering from various liver diseases ${ }^{4}$. With its anti-oxidant and anti-inflammatory properties, silibinin (also known as silybin) constitutes the most important part of this extract ${ }^{4}$. Thus, silymarin and/or silibinin have been found to exert favorable effects in various IRI models of different tissues, including liver, brain, kidney, and heart ${ }^{5-10}$. However, silibinin has not been explored in skeletal muscle IRI. Therefore, the aim of the present study was to investigate the potential protective effect of silibinin by measuring the parameters indicative of tissue injury and oxidative stress.

\section{Methods}

\section{Animal preparation and ischemia-reperfusion model}

Adult male Balb/c mice $(\sim 25 \mathrm{~g})$ were used in all experiments. Experiments were conducted in adherence with European Communities Council Directive (86/609/EEC) and approved by the Kahramanmaraş Sütçü İmam University Animal Care and Use Committee (protocol number: 2010/05/1). Animals were housed in a room with a temperature of $22 \pm 2^{\circ} \mathrm{C}$ and a humidity of $50-60 \%$ in a 12 hour day/night cycle. Intraperitoneal urethane (1 g/kg, Sigma, St Louis, MO, USA) was administered to attain sufficient anesthesia before the experiment and additional doses were applied where necessary. Each mouse was fixed on a pad and a domestic lamp (60W) was oriented above the animals in order to keep the body temperature at a constant level $\left(36 \pm 1^{\circ} \mathrm{C}\right)$. Thereafter, ischemia ( 2 hours) was achieved by the application of an elastic rubber band as high as possible on the left thigh of the mouse. After releasing the tourniquet, the limb was reperfused for 1 hour. Ischemia and reperfusion of the limbs were confirmed by the observation of the changes in colors of the paws. At the end of this period, gastrocnemius muscles from either side of the limbs were dissected out under general anesthesia. All samples were kept in - 20C until the assessment day.

\section{Experimental groups}

Mice were randomly distributed into four experimental groups. Each group consisted of six animals. Group I: Sham control group wherein mice were kept under anesthesia for 3 hours without a hind limb tourniquet operation. Group II: IRI group that received a hind limb tourniquet operation. Group III: IRI-ethanol group that received intraperitoneal ethanol $(10 \%)(\sim 1.6 \mathrm{~g} / \mathrm{kg} \mathrm{bw}$; $0.5 \mathrm{mI}) 10 \mathrm{~min}$ prior to reperfusion period. Group IV: IRI-silibinin group that received intraperitoneal silibinin $(50 \mathrm{mg} / \mathrm{kg} / 0.5 \mathrm{mI}$; Sigma, St Louis, MO, USA) 10 min prior to reperfusion period. The dose of silibinin was selected according to the literature ${ }^{9,10}$; however, since administration of $200 \mathrm{mg} / \mathrm{kg}$ was not tolerated by the mice (almost all died probably because of lung edema), the dose was lowered to $50 \mathrm{mg} / \mathrm{kg}$. Silibinin solution was prepared as follows: silibinin powder was initially dissolved in absolute ethanol and thereafter further dilutions were made by adding saline, constituting $10 \%$ ethanol in final solution.

\section{Biochemical measurements}

The tissues (gastrocnemius muscle) were weighed and blotted on filter paper and homogenized with three volumes of icecold $1.15 \%$ KCI. Superoxide dismutase (SOD) and catalase (CAT) activities and malondialdehyde (MDA) levels were measured in the supernatant obtained from centrifugation at $14.000 \mathrm{rpm}$.

MDA levels, reflects lipid peroxidation rate in tissue samples, were measured according to procedure of Ohkawa et al. ${ }^{11}$. The reaction mixture contained $0.1 \mathrm{ml}$ tissue sample, $0.2 \mathrm{ml}$ of 8.1 $\%$ sodium dodecyl sulphate, $1.5 \mathrm{ml}$ of $20 \%$ acetic acid and $1.5 \mathrm{ml}$ of $0.8 \%$ aqueous solution of TBA. The mixture $\mathrm{pH}$ was adjusted to 3.5 , and the volume was finally made up to $4.0 \mathrm{ml}$ with distilled water, and then $5.0 \mathrm{ml}$ of the mixture of n-butanol and pyridine $(15: 1, v / v)$ were added. The mixture was shaken vigorously. After centrifugation at $4000 \mathrm{rpm}$ for $10 \mathrm{~min}$, the absorbance of the organic layer was measured at $532 \mathrm{~nm}$. The protein concentration of the tissue samples was measured with Spectronic-UV 120 spectrophotometer by the method of Lowry ${ }^{12}$. MDA levels were 
expressed as $\mathrm{nmol} / \mathrm{mg}$ protein in tissue samples.

SOD activity was measured according to the method described by Fridovich ${ }^{13}$. This method employs xanthine and xanthine oxidase to generate superoxide radicals which react with p-iodonitrotetrazlium violet (INT) to form a red formazan dye which was measured at $505 \mathrm{~nm}$. Assay medium consisted of the $0.01 \mathrm{M}$ phosphate buffer, CAPS (3-cyclohexilamino-1propanesulfonicacid) buffer solution (50 mM CAPS, $0.94 \mathrm{mM}$ EDTA, saturated $\mathrm{NaOH})$ with $\mathrm{pH} 10.2$, solution of substrate $(0.05$ $\mathrm{mM}$ xanthine, $0.025 \mathrm{mM}$ INT) and $80 \mathrm{UL}$ xanthine oxidase. SOD activity was expressed as $\mathrm{U} / \mathrm{mg}$ protein in tissue samples.

CAT activities were determined by measuring the decrease in hydrogen peroxide concentration at $230 \mathrm{~nm}$ by the method of Beutler ${ }^{14}$. Assay medium consisted of $1 \mathrm{M}$ Tris HCI, $5 \mathrm{mM} \mathrm{Na} \mathrm{EDDT}_{2}$ buffer solution ( $\mathrm{pH} 8.0$ ), $1 \mathrm{M}$ phosphate buffer solution ( $\mathrm{pH} 7.0$ ) and $10 \mathrm{mM} \mathrm{H}_{2} \mathrm{O}_{2}$. CAT activity was expressed U/ $\mathrm{mg}$ protein in tissue samples.

Tissue viability for gastrocnemius muscle by the triphenyltetrazolium chloride method

At the end of ischaemia-reperfusion period, gastrocnemius muscles from either side of the hind limbs were excised and were rinsed in ice-cold Ringer's lactate solution. The muscle tissues were dissected free of blood vessels, nerves and fascia. The samples were kept in $-20^{\circ} \mathrm{C}$ until the day of assessment. The viability was then evaluated by the triphenyltetrazolium chloride method which assessed mitochondrial oxidative enzyme activity ${ }^{15}$. Briefly, gastrocnemius muscles were weighed and homogenized in $3 \mathrm{mI}$ of $0.25 \mathrm{M}$ sucrose. Additional sucrose was then added to make a 20 percent homogenate by weight. The homogenate was filtered through a fine stainless steel mesh to remove any remaining fragments of fascia. Protein content of the homogenate was determined by the method of Lowry et al. ${ }^{12}$. A $1 \mathrm{ml}$ aliquot of the homogenate was then mixed with $1 \mathrm{ml}$ of 0.15 percent triphenyltetrazolium chloride (Sigma, St.Louis, MO) in $0.033 \mathrm{M}$ phosphate buffer (dibasic sodium phosphate, $\mathrm{pH}$ 7.4). Reactions were performed in triplicate. The reaction mixture was stirred on a Vortex mixer and incubated at $39^{\circ} \mathrm{C}$ in a shaking water bath for 1 hour. The reaction was then stopped, and the mixture was diluted with $4 \mathrm{mI}$ of acetone, centrifuged for 10 minutes at 1,500 rpm, and absorbance of the clear red formazan dye was measured at 485 $\mathrm{nm}$ in a spectrophotometer (Shimadtzu, Japan). The absorbance per mg protein was calculated for each limb, and the activity of each ischemic limb was compared with the contralateral control limb to express the ischemic limb activity as a percentage of the control limb.

\section{Statistical analysis}

Data were expressed as mean \pm SEM and each group consisted of six animals. As normal distribution and homogeneity of variances were lacking in groups, non-parametric tests were performed. Therefore, data were analyzed by the use of KruskalWallis test, with the significance of individual comparisons being assessed by Mann-Whitney U test. $p$ values less than 0.05 accepted as significant.

\section{Results}

In the sham-control group (Group I), the viability of gastrocnemius muscle (left side) was $144 \pm 17 \%$ when compared with that of the contralateral control limb of the same animal (Figure 1). However, it significantly decreased to $28 \pm 9 \%$ in group II (IRI group), indicating a prominent damage within the muscle cells (Figure 1).

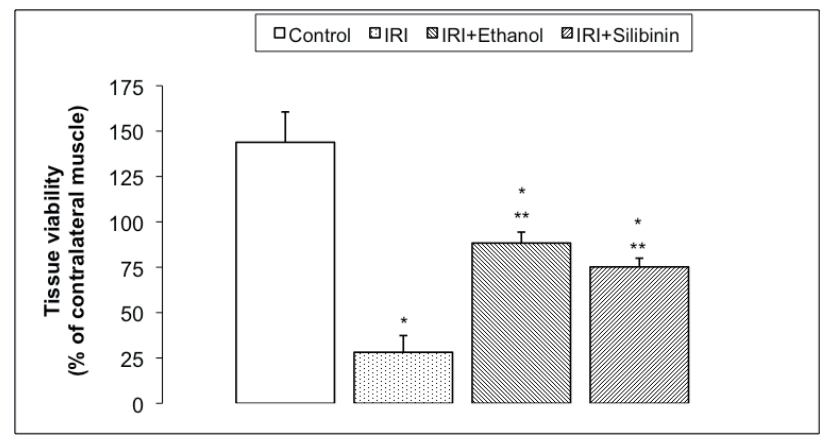

FIGURE 1 - Effects of ethanol (10\%, IP) and silibinin (50 mg/kg, IP) on viability of ischemic hindlimb, calculated as a percentage of the contralateral control muscle, in group I (Sham-control), group II (Ischemiareperfusion injury), group III (Ischemia-reperfusion injury+ethanol), and group IV (Ischemia-reperfusion injury + silibinin) $(\mathrm{n}=6$ per group). Data are expressed as mean \pm SEM and Kruskal-Wallis test and Mann-Whitney $\mathrm{U}$ test are performed. Significance is accepted $p<0.05$, * versus group I, ** versus group II.

On the other hand, administration of either ethanol (10\%) or silibinin (50 mg/kg) improved the recovery (Group III: $88 \pm 6 \%$; Group IV: 75 $\pm 5 \%$ ) (Figure 1). Additionally, malondialdehyde levels, an indicator of lipid peroxidation due to reactive oxygen species, were higher in group II than those in group I (Group I: $2.47 \pm 0.24 \mathrm{nmol} / \mathrm{mg}$ protein; Group II: $5.34 \pm 0.86 \mathrm{nmol} / \mathrm{mg}$ protein) (Figure 2). Nevertheless, application of silibinin $10 \mathrm{~min}$ prior to the reperfusion attenuated malondialdehyde levels below those detected in group II (Group IV: $1.77 \pm 0.37 \mathrm{nmol} / \mathrm{mg}$ protein) (Figure 2). 


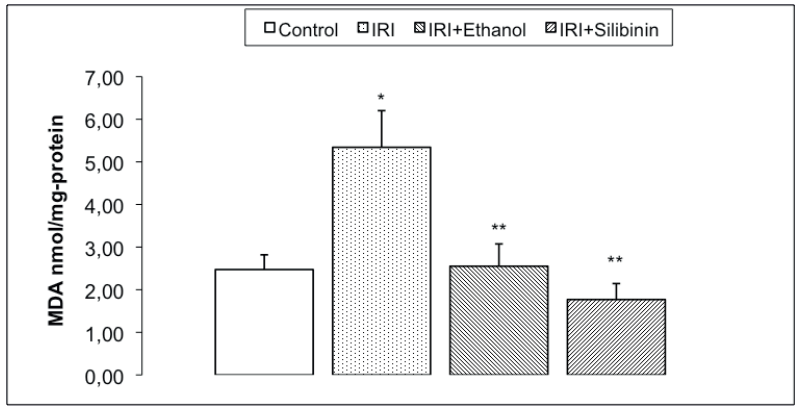

FIGURE 2 - Effects of ethanol (10\%, IP) and silibinin (50 mg/kg, IP) on malendialdehyde (MDA) levels in group I (Sham-control), group II (Ischemia-reperfusion injury), group III (Ischemia-reperfusion injury+ethanol), and group IV (Ischemia-reperfusion injury+silibinin) $(\mathrm{n}=6$ per group). Data are expressed as mean \pm SEM and Kruskal-Wallis test and Mann-Whitney U test are performed. Significance is accepted $p<0.05, *$ versus group I, ** versus group II.

Interestingly, malondialdehyde levels in ethanol administrated group were reduced as well (Group III: $2.55 \pm 0.52$ $\mathrm{nmol} / \mathrm{mg}$ protein) (Figure 2). IRI was found to significantly increase superoxide dismutase activity when a comparison was made between group I and II (Group I: $4.28 \pm 0.46 \mathrm{U} / \mathrm{mg}$ protein; Group II: $10.89 \pm 2.21 \mathrm{U} / \mathrm{mg}$ protein) (Figure 3).

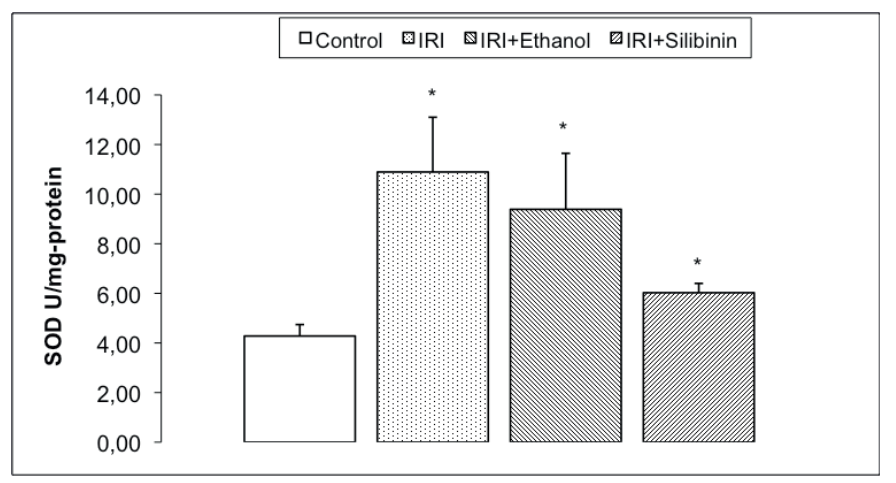

FIGURE 3 - Effects of ethanol $(10 \%$, IP) and silibinin $(50 \mathrm{mg} / \mathrm{kg}$, IP) on superoxide dismutase (SOD) levels in group I (Sham-control), group II (Ischemia-reperfusion injury), group III (Ischemia-reperfusion injury+ethanol), and group IV (Ischemia-reperfusion injury+silibinin) ( $n=6$ per group). Data are expressed as mean \pm SEM and Kruskal-Wallis test and Mann-Whitney $U$ test are performed. Significance is accepted $p<0.05, *$ versus group I, ** versus group II.

Yet neither silibinin nor ethanol diminished the levels of superoxide dismutase activity (Group III: $9.39 \pm 2.26 \mathrm{U} / \mathrm{mg}$ protein; Group IV: $6.02 \pm 0.38 \mathrm{U} / \mathrm{mg}$ protein) (Figure 3). Similarly, there were no statistical significant differences between groups regarding catalase activities (Group I: $96 \pm 17 \mathrm{U} / \mathrm{mg}$ protein; Group II: $185 \pm 41 \mathrm{U} / \mathrm{mg}$ protein; Group IV: $165 \pm 31 \mathrm{U} / \mathrm{mg}$ protein; Group IV: $110 \pm 6 \mathrm{U} / \mathrm{mg}$ protein) (Figure 4).

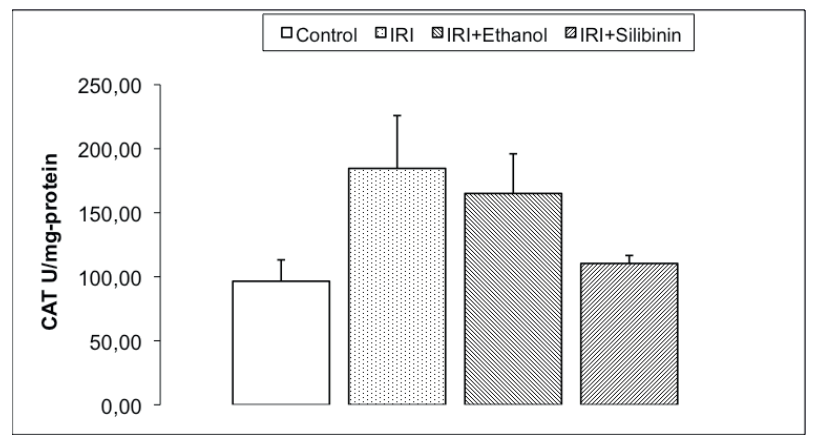

FIGURE 4 - Effects of ethanol (10\%, IP) and silibinin $(50 \mathrm{mg} / \mathrm{kg}, \mathrm{IP})$ on catalase (CAT) levels in group I (Sham-control), group II (Ischemiareperfusion injury), group III (Ischemia-reperfusion injury+ethanol), and group IV (Ischemia-reperfusion injury + silibinin) $(\mathrm{n}=6$ per group). Data are expressed as mean \pm SEM and Kruskal-Wallis test and Mann-Whitney $\mathrm{U}$ test are performed. Significance is accepted $p<0.05, *$ versus group I, ** versus group II.

\section{Discussion}

In the present study, it was shown that there is a significant difference between the viabilities of the left and the right legs in the sham control group. Each mouse was fixed on a pad by the use of an adhesive tape, which served to stabilize the hind limbs on the corresponding side of the pad. Perhaps, an asymmetry occurred during this procedure may attenuate the blood stream to one of the legs in comparison with the other. This may lead an imbalance in mitochondrial oxidative enzyme activities of the left and right legs, constituting the basis of the variation seen in the sham group. Despite the presence of this surprising result, IRI model applied in mice brought about an intensive injury as the left gascrocnemius muscle viability was greatly lower that of the contralateral control muscle. In harmony, malondialdehyde levels, an indicator of lipid peroxidation, were higher in IRI group than those in the control group. Taken together, these data show that there may be a close relationship between oxidative stress-related membrane injury and tissue damage, supporting the notion that anti-oxidant treatment may be a rational option in attenuating IRI. Thus, administration of silibinin $10 \mathrm{~min}$ prior to reperfusion significantly protected the tissue from IRI since tissue viability of the left leg was nearly identical to that seen in sham-control group. This effect could be due to its anti-oxidant effect as silibinin also prevented the increase in malondialdehyde levels. However, the solvent of silibinin, ethanol $(10 \%, \sim 1.6 \mathrm{~g} / \mathrm{kg})$, also prevented the tissue injury and malondialdehyde increments in the present study. Similarly, ethanol $(10 \%, 1 \mathrm{~g} / \mathrm{kg})$ given $15 \mathrm{~min}$ prior to gut ischemiareperfusion protected the liver from injury in Wistar rats ${ }^{16}$. Indeed, a study performed on mice showed that moderate antecedent ethanol exposure provides protection for the kidneys against subsequent 
IR-induced injury ${ }^{17}$. In contrast, ethanol (1.9\%) was shown to have a tendency to increase superoxide anion production in a model of cold preservation-warm reperfusion liver injury and this effect was detected to be reversed by the application of silibinin in a previous study $^{5}$. In fact, silibinin is sparingly soluble in aqueous buffers; therefore ethanol, dimethyl sulfoxide, and dimethyl formamide are generally being used to dissolve this chemical. Ethanol was selected in the present study as dimethyl sulfoxide had been known to exert anti-oxidant effects ${ }^{18}$, which could interfere with the effect of silibinin. However, ethanol, unfortunately, turned out to be a factor complicating the interpretation of silibinin action.

The favorable effect of ethanol, which was coincidentally detected in the present study, may be attributed to its anti-oxidant action since it has been accepted to have the ability to scavenge free radicals ${ }^{19,20}$. Our finding that ethanol reduces increased malondialdehyde levels due to ischemia-reperfusion insult supports this assumption. Thus, ethanol demonstrated protection from ischemia-reperfusion-evoked CA1 hippocampal pyramidal cell death in the gerbils and antioxidant activity was assumed to account for this effect ${ }^{18}$. In harmony, moderate exposure of ethanol for four weeks to rats with ischemia-repefusion injury exerted protective effects through mechanisms regulating oxidative stress $^{20}$

Despite the beneficial effect of ethanol per se observed in the present study, we cannot exclude the possibility that silibinin has the potential to alleviate IRI. The favorable effect of silibinin may be masked by the presence of ethanol effect and this can be avoided by the use of water soluble form of silibinin in further studies. Thus, several lines of evidence show its beneficial effects in IRI of distinct origin ${ }^{5-8}$.

As to superoxide dismutase, there was a significant enhancement in IRI group when compared with the control values in the present study. In principle anti-oxidant enzymes tend to display decreased activities upon oxidative stress due to the loss of the cell integrity. However, the paradoxical result obtained in the present study may be explained by the fact that the increase in SOD activity may be the result of de novo synthesis of SOD in response to the noxious challenge as an adaptation mechanism. Although not significant the increase seen in catalase activity may be explained in a same manner. An alternative explanation for this surprising result is that SOD and catalase activities were determined in $14.000 \mathrm{rpm}$ supernatant in the present study. This could open up the possibility that the mitochondrial part of SOD and catalase was not measured in sham control group, because no detergent was obviously used in the homogenisation procedure to break the mitochondria (e.g. 1\% triton). Thus, it is certainly possible, that after ischemia-reperfusion insult there may be more mitochondria being damaged, resulting in the release of mitochondrial SOD/Catalase into the cytosol and thus the supernatant. This could explain the increase in SOD/Catalase measured in the supernatant of the IRI muscle. Nevertheless, the ineffectiveness of ethanol and silibinin on these parameters is a predictable fact as enzyme activities have already been updated by ischemia-reperfusion insult.

\section{Conclusion}

Ethanol seems to be effective in attenuating ischemiareperfusion injury in skeletal muscle and no definite conclusion can be made on silibinin effect.

\section{References}

1. Khanna AK, Cowled PA, Fitridge RA. Nitric oxide and skeletal muscle reperfusion injury: current controversies (research review). J Surg Res. 2005;128:98-107.

2. Wang WZ, Baynosa RC, Zamboni WA. Update on ischemiareperfusion injury for the plastic surgeon. Plast Reconstr Surg. 2011;128:685e-92.

3. Lindsay T, Romaschin A, Walker PM. Free radical mediated damage in skeletal muscle. Microcirc Endothelium Lymphatics. 1989;5:15770 .

4. Luper S. A review of plants used in the treatment of liver disease: part 1. Altern Med Rev. 1998;3:410-21.

5. Ligeret H, Brault A, Vallerand D, Haddad Y, Haddad PS. Antioxidant and mitochondrial protective effects of silibinin in cold preservationwarm reperfusion liver injury. J Ethnopharmacol. 2008;115:507-14.

6. Hou YC, Liou KT, Chern CM, Wang YH, Liao JF, Chang S, Chou YH, Shen YC. Preventive effect of silymarin in cerebral ischemiareperfusion-induced brain injury in rats possibly through impairing NF- $\mathrm{kB}$ and STAT-1 activation. Phytomedicine. 2010;17:963-73.

7. Senturk H, Kabay S, Bayramoglu G, Ozden H, Yaylak F, Yucel M, Olgun EG, Kutlu A. Silymarin attenuates the renal ischemia/ reperfusion injury-induced morphological changes in the rat kidney. World J Urol. 2008;26:401-7.

8. Rao PR, Viswanath RK. Cardioprotective activity of silymarin in ischemia-reperfusion-induced myocardial infarction in albino rats. Exp Clin Cardiol. 2007;14:179-87.

9. Valenzuela A, Guerra R. Protective effect of the flavonoid silybin dihemisuccinate on the toxicity of phenylhydrazine on rat liver. FEBS Lett. 1985;181:291-4.

10. Valenzuela A, Guerra R, Valenzuela A, Barria T, Guerra R, Garrido A. Inhibitory effect of the flavonoid silymarin on the erythrocyte hemolysis induced by phenylhydrazine. Biochem Biophys Res Commun. 1985;126:712-8.

11. Ohkawa H, Ohishi N, Yagi K. Assay for lipid peroxides in animal tissues by thiobarbituric acid reaction. Anal Biochem. 1979;95:3518.

12. Lowry $\mathrm{OH}$, Rosebrough NJ, Farr AL, Randall RJ. Protein measurement with the folin phenol reagent. J Biol Chem. 1951;193:265-75.

13. Fridovich I. Superoxide dismutases. Adv Enzymol Relat Areas Mol Biol. 1974;41:35-97.

14. Beutler E. Catalase. In: Beutler E, editor. Red cell metabolism. New 
York: Grune and Stratton Company; 1975. p.89-90.

15. Belkin M, Brown RD, Wright JG, LaMorte WW, Hobson RW. A new quantitative spectrophotometric assay of ischaemic-reperfusion injury in skeletal muscle. Am J Surg. 1988;156:83-6.

16. Horie Y, Yamagishi Y, Kato S, Kajihara M, Kimura H, Ishii H. Ethanol modulates gut ischemia/reperfusion-induced liver injury in rats. Am J Physiol Gastrointest Liver Physiol. 2002;282:G640-6.

17. Yuan Q, Hong S, Han S, Zeng L, Liu F, Ding G, Kang Y, Mao J, Cai M, Zhu Y, Wang QX. Preconditioning with physiological levels of ethanol protect kidney against ischemia/reperfusion injury by modulating oxidative stress. PLoS One. 2011;6:e25811.

18. Phillis JW, Estevez AY, O'Regan MH. Protective effects of the free radical scavengers, dimethyl sulfoxide and ethanol, in cerebral ischemia in gerbils. Neurosci Lett. 1998;244:109-11.

19. Del Maestro RF, Thaw HH, Bjork J, Planker M, Arfors KE. Free radicals as mediators of tissue injury. Acta Physiol Scand. 1980;492:43-57.

20. Addolorato G, Di Campli C, Simoncini M, Pasini P, Nardo B, Cavallari A, Pola P, Roda A, Gasbarrini G, Gasbarrini A. Oxygen free radical production in rat liver: dose-related effect of ethanol on reperfusion injury. Dig Dis Sci. 2001;46:1057-66

\section{Correspondence:}

Yusuf Ergün

Kahramanmaraş Sütçü İmam University

School of Medicine, Department of Pharmacology

46100, Kahramanmaraş, Turkey

Phone: +90 3442212337

Fax: +90 3442212371

yusufergun@yahoo.com

Received: October 15, 2012

Review: December 17, 2012

Accepted: January 18, 2013

Conflict of interest: none

Financial source: none

${ }^{1}$ Research performed at Department of Pharmacology, Faculty of Medicine, Kahramanmaraş Sütçü İmam University, Kahramanmaraş, Turkey. 